\title{
土木工程施工中的钢结构技术研究
}

詹显龙

安徽富煌建筑设计研究有限公司

DOI:10.32629/btr.v2i3.1967

[摘要] 在土木工程施工中, 我们经常会用到钢结构技术, 很多工程利用钢结构技术能够获得更好的工程特性, 在一些大型厂 房、高层建筑、各种场馆的建设中, 该技术的应用尤为广泛, 尤其是高层建筑的建设, 由于钢结构技术拥有结构强度高、安全性 高、环保性好等诸多优点现在已经成为了土木工程建设中常用的建设技术, 本文将针对钢结构技术进行分析。

[关键词]土木工程; 钢结构技术; 结构建筑

随着我国城市化进程的不断推进, 城市建筑需求也逐渐 增多, 为了满足人民居住需求, 现阶段高层民用住宅已经成 为了建筑工程的主要内容, 而在进行高层建筑建设的过程中, 钢结构技术凭借着其高质量、短工期和可靠性成为了当前高 层中的常用技术, 在使用钢结构技术进行建设的过程中, 我 们必须要重视其技术的规范性才能够达到相关建设的质量 要求, 下面我们就对钢结构技术相关情况进行分析。

\section{1 土木工程施工中钢结构技术的应用情况}

1.1 选材与连接

在钢结构建筑中, 其建筑的整体强度主要取决于其建设 材料及连接方式, 在当前常见的钢结构建筑中, 我们日常选 择的钢结构建设材料主要有以下几种: 普通碳素钢、优质碳 素钢、以及低合金高强度钢等, 这其中碳素钢由于其强度较 高且受力不易产生形变, 所以常用于土木工程建筑中, 强度 和硬度是建材用于工程之中的一个重要指标, 这是保障工程 质量的重要材料因素。在进行钢结构建筑施工过程中, 我们 常用的材料连接方式为焊接和螺栓连接, 焊接作为金属材料 常用的连接方式, 在结构强度上能够达到较高的效果, 螺栓 连接是利用螺栓结构来进行各部件之间的接合, 螺栓连接还 能够具体分为普通螺栓和高强度螺栓连接, 在不同的建筑部 位和不同的工程类型中, 使用何种连接方式都需要根据实际 情况的需求来具体决定 ${ }^{[1]}$ 。

\section{2 材料与设备}

由于钢结构构件整体质量较大, 同时其体积也比较大, 所以在实际进行建设之前需要在施工现场预留存放空间, 空 间不宜过小, 应该能够确保放置相关钢结构材料, 同时我们 需要注意钢结构材料在施工现场的存放, 不能放置在潮湿和 易锈蚀的环境中, 同时钢结构材料在运输存放过程中可能会 因外力而导致一定程度的形变, 钢结构材料一旦出现形变将 会严重影响其工程质量, 所以, 我们需要在施工前对发生性 变的钢结构材料进行修复整备, 在进行钢结构材料调动调整 的过程中, 我们需要大型装吊设备来配合完成该过程, 在设 备使用过程中, 我们要注意确保设备与钢结构材料的装吊平 稳, 保障材料的运输安全性, 对于装吊设备要定期检查其机 械状态, 妥善进行维护 ${ }^{[2]}$ 。

\section{3 吊装技术}

在进行钢结构材料拼接的过程中, 我们需要将钢结构材 料进行吊装处理, 吊装过程决定着钢结构建筑的施工进度和 施工速度等问题, 同时也在很大程度上影响着施工的安全性, 所以吊装工作是钢结构建筑施工中的重要步骤之一, 在进行 吊装之前, 我们需要对工程整体进行分析, 首先要明确工程 结构特点, 清楚各结构连接点位置, 通过对工程的整体分析 来确定具体的吊装技术。吊装技术是将相关钢结构材料吊装 至具体连接位置的重要步骤, 这也是将相关材料进行连接前 的必要操作, 想要保障工程安全快速进行, 吊装技术的确定 是非常关键的, 首先应该明确吊装设备的选择, 确定吊装设 备的规格和具体操作步骤, 其次要根据需要吊装的钢结构部 件来具体进行吊装前的准备工作, 确保实际吊装过程的安全 与高效 ${ }^{[3]}$ 。

\section{4 焊接技术}

在钢结构建筑施工中, 焊接技术是保障材料连接质量的 重要技术, 在进行焊接过程中, 我们需要注意焊接的位置与 焊接技术的选择, 焊接作为连接钢结构材料的一种接合技术 其重要性是不言而喻的, 我们想要确保工程质量, 首先就要 保障钢结构的整体强度, 而焊接技术正是决定钢结构整体强 度的重要技术之一。利用焊接来完成钢结构材料的连接进而 完成工程施工是非常高效的, 相较于传统的混凝土施工, 焊 接施工能够保障很高的施工效率, 但是我们也应注意到焊接 中容易出现的问题, 首先是焊接点的选择, 钢结构材料的焊 接连接过程涉及到很多相关建筑专业知识, 一旦没有良好掌 握焊接点, 将会导致整个钢结构框架的强度下降, 造成质量 隐患, 其次是焊接工艺的选择, 在不同材料不同焊接部位, 我 们需要根据其受力情况选择不同的焊接技术, 这些都需要根 据实际情况具体分析, 有的需要对接接头进行焊接, 有的需 要进行点焊操作, 还有的需要根据实际连接角度和结合方式 进行多方向上的整体焊接, 就焊接技术而言, 其目的只有一 个, 那就是保障焊接后的钢结构构件连接牢固, 整体强度能 够得到保障 ${ }^{[4]}$ 。

\section{5 防锈技术}

采用钢结构来进行建设的建筑, 整体结构焊接完毕后需 
要进行整体钢结构的防锈处理, 由于钢结构的金属特性, 如 果不进行有效的防锈处理, 其很多有可能发生锈蚀, 一旦出 现锈蚀现象就会影响钢结构建筑的整体强度, 所以我们需要 对完成焊接的钢结构整体进行防锈处理, 当前我们一般都会 采用喷涂防锈漆的方式来进行表层防锈处理, 在进行防锈漆 的喷涂前, 首先我们需要对钢结构表面进行严格的清理, 首 先是除去当前已有的锈迹, 使用钢丝刷和砂纸进行反复打磨, 去除全部锈迹后进行底漆的喷涂, 喷涂底漆是为了增加防锈 漆层的整体抗锈蚀效果, 完成底漆喷涂后我们需要对整体进 行晾晒, 保障底漆彻底干燥, 之后在进行油漆涂刷工作, 在涂 刷过程中一定要注意油漆的均匀, 不能让不同部位的油漆厚 度不同, 这样容易造成表层油漆的脱落, 要充分保证漆面厚 度均匀, 充分达到防锈防腐蚀的效果。

\section{2 土木工程施工中钢结构技术有效应用策略}

\section{1 保障原材料质量}

在任何工程项目中, 想要确保工程质量, 第一步就要保 障其原材料的质量, 作为钢结构建筑来讲, 其钢结构材料质 量的水平直接影响到建筑的整体质量, 所以我们必须从原材 料上满足工程质量要求, 在工程设计过程中我们就应该深刻 研究工程中需要使用的钢结构材料规格, 根据设计指标来确 定其具体的材料要求, 在材料选择的过程中, 首先要针对厂 家进行篮选, 选择那些具有生产资质, 能够提供合格材料的 大厂进行合作, 同时需要其出示相关批次产品的合格证书。 同时我们也应该在施工中的其他材料上保障质量, 例如焊接 材料和其他施工用材, 只有全面保障了施工材料的质量稳定, 我们的整体工程质量才能有一个好的保障 ${ }^{[5]}$ 。

\section{2 确保材料存放安全}

由于钢结构建筑在施工前会有大量的钢结构材料堆放, 所以在这一过程中我们需要充分保障这些材料的安全, 首先 是材料运输至存放场地的过程中, 要充分保障材料不受外力 的影响而导致变形, 其次我们要尽量缩短钢结构材料的堆放 时长, 由于材料本身的金属特性, 堆放时间越长, 其产生锈蚀 和变形的风险就越高, 对于其后期工程应用的影响也就越大, 所以我们应该尽可能的缩短材料堆放时长, 同时在使用堆放 材料进行施工的过程中, 我们一定要仔细检查材料状态, 检 查其形态是否有明显变化, 是否产生了锈蚀或者裂痕, 要在 确保材料符合施工应用要求后才能将材料投入工程施工中 去, 对于焊接点来讲, 其在进行焊接之前必须进行处理, 保证 焊接点的整洁和完整, 保障焊接连接质量, 确保工程质量 ${ }^{[6]}$ 。
2.3 提高工人安全意识

在钢结构建筑施工过程中我们不仅要在技术上和设备 上保障工程建设的质量及效率, 同时我们也应该从施工人员 的安全意识上来进行安全施工的教育工作, 由于钢结构工程 施工过程中涉及到的相关操作步骤非常多, 所以这其中有非 常多的细节值得注意, 在钢结构建筑施工中, 我们还会涉及 到相关的混凝土施工, 所以, 我们必须注意混凝土施工对于 工程整体的影响, 由于施工人员在整体施工过程中可能存在 安全意识不足的现象, 所以其对于一些相关安全隐患的关注 可能不到位, 例如混凝土施工与天气的关联, 混凝土施工受 天气影响是非常大的, 很容易因为天气原因而使建筑内部产 生内应力而降低建筑整体强度, 这些都是非常值得关注的, 我们应该加强施工人员的安全教育和技术培训, 明确安全操 作的重要性, 确保工程整体建设的顺利进行 ${ }^{[7]}$ 。

\section{3 结束语}

为了更好地实现钢结构技术在当前建筑施工中的应用， 我们必须在钢结构建筑施工过程中重点注意其原材料的选 择以及吊装焊接工艺的选择, 同时注意材料的存放以及人员 安全意识的培养工作, 提升整体工程质量, 为钢结构技术的 发展提供有利的前景。

\section{[参考文献]}

[1]鲁滨.土木工程施工中的钢结构技术研究 [J].房地产 导刊,2019,(5):105.

[2]黄燕.土木工程施工中的钢结构技术研究 [J]. 建筑工 程技术与设计,2018,(32):1042.

[3]曾浩哲.土木工程施工中钢结构技术的研究 [J].建筑 工程技术与设计,2018,(29):223.

[4]梁学会.土木工程施工中钢结构技术的应用研究 [J]. 装饰装修天地,2018,(19):241.

[5]李汝斌.建筑工程钢结构检测的技术运用研究[J]. 装 饰装修天地,2019,(4):92.

[6]宁厚美,郭超.超高层建筑钢结构施工关键技术研究 [J].建筑工程技术与设计,2018,(35):1618.

[7]张彦平.高层建筑钢结构施工技术要点研究 [J].建筑 工程技术与设计,2018,(34):552.

\section{作者简介：}

詹显龙,(1985--),性别: 男,汉族,安徽省六安市人,硕士研 究生, 工程师,结构工程,一级注册结构工程师。 